\title{
Avaliação citológica e microbiológica do lavado broncoalveolar em cães hígidos
}

\section{Cytological and microbiologic evaluation of bronchoalveolar lavage in healthy dogs}

\author{
Alessandra Melchert ${ }^{1 *}$; Yudney Pereira da Motta ${ }^{2}$; \\ Rogério Giuffrida ${ }^{3}$; Cecília Braga Laposy ${ }^{4}$
}

\section{Resumo}

\begin{abstract}
Objetivando-se padronizar a técnica transtraqueal para coleta do lavado broncoalveolar não broncoscópico, bem como caracterizar a celularidade e microbiota residente em lavados do trato respiratório inferior (TRI) de cães normais, da região de Presidente Prudente, foram estudados 30 cães saudáveis, machos e fêmeas, sem raça definida, adultos. Os animais foram tranqüilizados e então submetidos à coleta do lavado, pela técnica transtraqueal. Foram isolados microrganismos bacterianos e fúngicos, respectivamente em 46,67\% e 16,67\% dos animais pesquisados. Em 43,3\% das amostras foram isolados dois ou mais microrganismos. As médias de unidades formadoras de colônia (UFC) por mililitro de lavado broncoalveolar, para bactérias e fungos, foram de $21540 \pm 55289$ e 13,33 $\pm 43,4$, respectivamente. A citologia revelou predominância de macrófagos alveolares e pequenas quantidades de neutrófilos, linfócitos, eosinófilos, células epiteliais e bactérias, além de correlação positiva entre o escore de macrófagos e as contagens de UFC de bactérias. A técnica avaliada mostrou-se adequada e segura.
\end{abstract}

Palavras-chave: Lavado broncoalveolar, cães, cultura qualitativa, citologia

\begin{abstract}
The aim of this study was to standardize the transtracheal technique to collect the broncoalveolar lavage fluid without broncoscopy and to determine the normal cytologic and microbiologic findings of the lower respiratory tract wash, in healthy dogs. Thirty adult dogs (12 males and 18 females), age from one to eight years old, were submitted to sedation in order to permit the bronchoalveolar lavage. Bacterial and fungal microorganisms were isolated in $46.67 \%$ and $16.67 \%$ of the lavage samples, respectively. In $43.3 \%$ out of the samples were isolated two or more microorganisms. Mean and standard deviation of colony-forming units (CFU)/ml were $21540 \pm 55298$ and $13.33 \pm 43.4$ for bacterial and fungal organisms, respectively. In cytological evaluation, alveolar macrophage was the predominant cell. Small amounts of neutrophils, lymphocytes, eosinophils, epithelial cells and bacteria were observed, besides positive correlation between macrophage score and bacteria CFU. The technique was adequated and showed wide margin of security.
\end{abstract}

Key words: Bronchoalveolar lavage, dogs, culture, cytology

\footnotetext{
${ }^{1}$ Prof. Dra. Depto de Clínica Médica de Pequenos Animais, UNOESTE, Presidente Prudente, SP, Brasil. E-mail: alessandravet@unoeste.br.

2 Residente do programa de Clínica Médica de Pequenos Animais, UNOESTE, Presidente Prudente, SP, Brasil.

3 Prof. Msc. Depto de Apoio Diagnóstico, UNOESTE, Presidente Prudente, SP, Brasil.

4 Prof. Dra. Depto de Apoio Diagnóstico, UNOESTE, Presidente Prudente, SP, Brasil.

* Autor para correspondência
} 


\section{Introdução}

Moléstias do trato respiratório inferior (TRI) são comuns na clínica de pequenos animais (CORCORAN, 2004). A abordagem diagnóstica de animais com sinais de doença do TRI inclui anamnese, exame físico, radiografias torácicas (HAWKINS, 2006) e visualização direta das vias aéreas por broncoscopia (HAWKINS; DENICOLA, 1990). Apesar destas técnicas de diagnóstico serem úteis na identificação e localização do processo clínico, nem sempre fornecem um diagnóstico etiológico (CORCORAN, 2004). Assim, exames posteriores podem ser necessários e incluem avaliação de amostras colhidas do TRI, testes para doenças específicas e hemogasometria do sangue arterial (HAWKINS, 2006). As avaliações citológica e microbiológica do TRI podem auxiliar no estabelecimento de um diagnóstico etiológico (CORCORAN, 2004) e na compreensão do mecanismo da doença e determinar se há ou não infecção (bacteriana ou fúngica) presente (COLLEGE OF VETERINARY MEDICINE CVM, 2004), fornecendo um direcionamento na seleção da terapia apropriada (HAWKINS, 1995).

O lavado broncoalveolar não broncoscópico obtido a partir do método transtraqueal fornece material útil para citologia e microbiologia (HAWKINS, 1995), sendo indicado nos casos em que a anestesia geral não é segura, porém, sedação ou tranqüilização são usualmente indicadas. A técnica emprega um cateter guiado por agulha, introduzido percutaneamente no interior da traquéia, sendo a mais comumente utilizada em cães (BERKWITT; PRUETER, 1998; HAWKINS, 2006; PADRID, 2000).
Este trabalho tem como objetivo avaliar a colheita de lavado broncoalveolar através da técnica transtraqueal e estabelecer a microbiota e citologia do TRI em cães normais, da região de Presidente Prudente, SP.

\section{Material e métodos}

Foram estudados trinta cães, doze machos e dezoito fêmeas, sem raça definida, com idades entre um e oito anos e peso corporal entre cinco e dezessete quilos $(\mathrm{kg})$, em perfeito estado geral de saúde, selecionados através de exame clínico e hemograma normais, da região de Presidente Prudente, SP.

Para colheita do lavado broncoalveolar os animais foram anestesiados com tiopental sódico*, precedido da aplicação de acepromazina*. Posicionou-se a cabeça do cão em angulação de 45 graus com o plano horizontal. O líquido do lavado broncoalveolar foi colhido com uso de cateter* intravenoso longo (cerca de $30 \mathrm{~cm}$ ) por entre agulha de calibre de 18 gauge. A pele foi preparada cirurgicamente como mostra a figura 1 (tricotomia e antissepsia local), inserindo-se a agulha na região correspondente ao ligamento cricotireóideo, caracterizado como uma depressão imediatamente acima da cartilagem cricóide (Figura 2). O cateter foi inserido através da agulha no interior das vias respiratórias avançando além da carina, instilando-se solução salina estéril ${ }^{*}$, na dose de 20 a $35 \mathrm{~mL}$ (Figura 3). Imediatamente após este procedimento, várias tentativas de aspiração do líquido foram feitas, procurando-se recuperar, no mínimo, $2 \mathrm{~mL}$ do total infundido (Figura 4). A amostra foi encaminhada para processamento citológico e culturas bacteriana e fúngica.

\footnotetext{
* Thiopentax - Cristália, São Paulo, SP, Brasil

* Acepran 0,2\% ${ }^{\circledR}$, Univet S/A, São Paulo, SP, Brasil.

* Venocath - Abbot Ltda., Irlanda.

* Cloreto de Sódio 0,9\% ${ }^{\circledR}$, Fresenius Kabi, Rio de Janeiro, RJ, Brasil.
} 


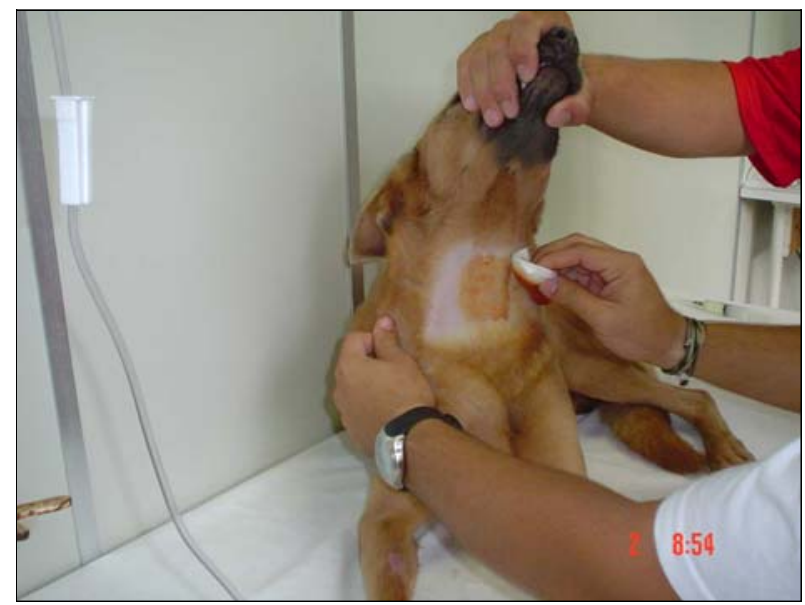

Figura 1. Tricotomia e antissepsia local.

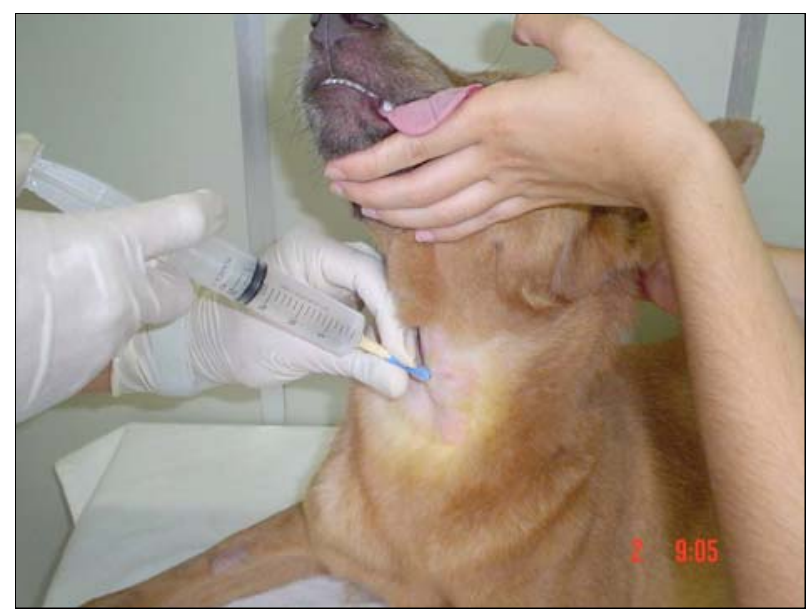

Figura 3. Infusão de solução salina estéril.

Após a colheita, as amostras foram centrifugadas a 2500 rpm (Centrífuga Bio-Eng BE-400) durante cinco minutos. O sobrenadante foi desprezado e com o sedimento elaborou-se um esfregaço, submetido à coloração do tipo Giemsa. A avaliação citológica foi realizada inicialmente na objetiva de 10 vezes, a fim de se observar se toda a área útil do esfregaço foi devidamente corada e se existia celularidade representativa suficiente para interpretação. Então, visualizou-se o esfregaço com objetiva de 100 vezes para identificação qualitativa dos tipos celulares e possíveis alterações morfológicas (TYLER et al., 1999). O score citológico preconizado neste trabalho como padrão foi de 0 (para ausência de celularidade); 1 (para visualização de até um tipo celular por

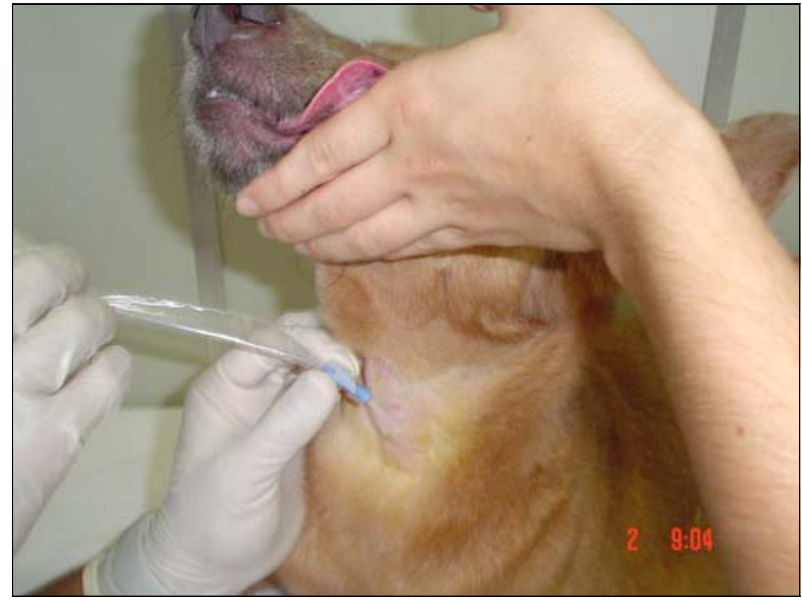

Figura 2. Inserção da agulha na região correspondente ao ligamento cricotieoideo e colocação do cateter.

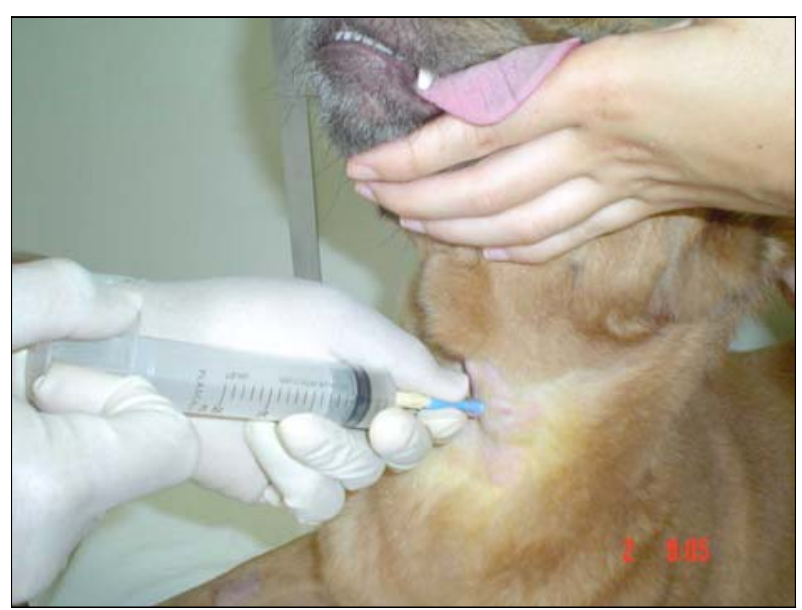

Figura 4. Aspiração do líquido para recuperação de no mínimo $2 \mathrm{~mL}$ do total infundido.

campo); 2 (para até cinco células por campo visualizado) e 3 (para celularidade superior a cinco em cada campo contado).

Para avaliar a presença de bactérias e fungos no lúmem traqueal canino, os lavados broncoalveolares foram submetidos à cultura quantitativa seguindo as especificações de Quinn et al. (1994). Os lavados broncoalveolares foram diluídos em série em solução salina obedecendo-se as proporções de 1:10 e 1:100. Das amostras de lavado broncoalveolar e as suas respectivas diluições retirou-se $0,1 \mathrm{~mL}$ para semeadura por película em três placas contendo ágarsangue ovino desfibrinado. As placas foram incubadas em aerobiose a $37^{\circ} \mathrm{C}$ por 72 horas. Após 
este período, foram computadas as Unidades Formadoras de Colônia por $\mathrm{ml}$ de lavado (UFC/mL) avaliando-se as três placas semeadas. As colônias bacterianas observadas foram classificadas preliminarmente segundo suas características morfotintoriais e posteriormente segundo seu comportamento bioquímico frente às provas usuais para identificação de microrganismos bacterianos (QUINN et al., 1994).

Paralelamente à semeadura para identificação bacteriana, $0,1 \mathrm{~mL}$ da amostra pura de lavado broncoalveolar e suas respectivas diluições a 1:10 e 1:100 foram semeadas superficialmente com auxílio de alça de Drigalski em placas contendo ágar Sabouraud-dextrose suplementado com $0,4 \%$ de cloranfenicol e incubadas a $37^{\circ} \mathrm{C}$ por 7 dias em aerobiose. Após computar-se o número as UFC $/ \mathrm{mL}$ de lavado, as mesmas foram identificadas segundo suas características macro e micro-morfológicas (LACAZ et al., 1998).

Para evidenciar correlações estatísticas entre os parâmetros citológicos avaliados no lavado broncoalveolar e as contagens totais obtidas foi utilizado o teste de correlação de Spearman para amostras não paramétricas. Procedimento idêntico foi utilizado para correlacionar as UFC bacterianas obtidas com idade e peso dos animais pesquisados. Para comparar as UFC bacterianas obtidas para machos e fêmeas utilizou-se o teste de Mann-Withney para amostras não-paramétricas. Para comparar os escores obtidos para as diferentes populações celulares observadas no exame citológico dos lavados broncoalveolares utilizou-se o teste de Friedman para amostras relacionadas (CURI, 1997).

\section{Resultados e Discussão}

Não foram observadas complicações após o uso da técnica transtraqueal para a colheita do lavado broncoalveolar. Recuperou-se pelo menos $2 \mathrm{mLde}$ material em 29 animais (96,6\%), com média de 2,6 $\mathrm{mL}$ de volume.

Foram isolados microrganismos bacterianos e fúngicos, respectivamente em $46,67 \%$ e $16,67 \%$ dos animais pesquisados. Em 43,33\% das amostras foram isolados dois ou mais microrganismos. As contagens de microrganismos obtidas a partir dos 30 cães pesquisados variaram de 0 a 2,32 x $10^{5} \mathrm{UFC} /$ $\mathrm{ml}$ para bactérias e de 0 a $2 \times 10^{2} \mathrm{UFC} / \mathrm{ml}$ para microrganismos fúngicos. As contagens médias e respectivos desvios-padrões para bactérias e fungos

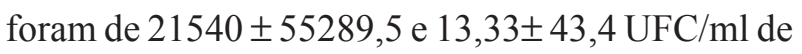
lavado, respectivamente. As médias de contagens de UFC não diferiram entre os sexos, nem foram correlacionadas estatisticamente ao peso e idade do animal. Das espécies de microrganismos isoladas, $72,2 \%$ eram Gram-positivas e 27,8\%, Gramnegativas. As prevalências observadas para os diferentes microrganismos isolados estão apresentadas na Tabela 1.

Os resultados da análise citológica dos lavados broncoalveolares estão apresentados na Tabela 2. Quando se comparou os escores obtidos para as diferentes populações celulares, observou-se significativa predominância de macrófagos alveolares sobre todas as outras populações $(p<0,001)$.

Embora a técnica transtraqueal seja utilizada para avaliação das grandes vias aéreas, o predomínio dos macrófagos deveu-se a recuperação de fluido das pequenas vias aéreas e alvéolos, pois o cateter foi estendido para os pulmões além da carina (HAWKINS, 2006).As outras populações celulares encontradas em pequenas quantidades correspondem a neutrófilos, linfócitos, eosinófilos e células epiteliais. Foram encontradas também hemácias íntegras. Observou-se correlação estatística positiva entre os escores observados para presença de macrófagos alveolares e as UFC/mL obtidas.

Segundo Corcoran (2004), McCullough e Brinson (1999) e Padrid (2000), os macrófagos alveolares são predominantes seguidos por pequenos números de linfócitos, eosinófilos, células epiteliais e bactérias. Hemácias também podem ser encontradas (McCULLOUGH; BRINSON, 1999). Os resultados da análise citológica encontrados neste trabalho, apesar de serem qualitativos, e não quantitativos, concordam com os valores estabelecidos na literatura para cães saudáveis. 
Tabela 1. Prevalência dos microrganismos bacterianos e fúngicos isolados a partir do lavado broncoalveolar de cães hígidos.

\begin{tabular}{lcc}
\hline Microrganismos bacterianos & $\mathbf{n}^{\mathbf{0}}$ & $\mathbf{\%}$ \\
\hline Micrococcus luteus & 6 & $20 \%$ \\
Staphylococcus aureus & 4 & $13,3 \%$ \\
Streptococcus não-hemolítico & 4 & $13,3 \%$ \\
Bordetella bronchiseptica & 3 & $10 \%$ \\
Corynebacterium sp & 3 & $10 \%$ \\
Micrococcus varians & 3 & $10 \%$ \\
Alcaligenes sp & 2 & $6,67 \%$ \\
Bacillus sp & 2 & $6,67 \%$ \\
Staphylococcus haemolyticus & 2 & $6,67 \%$ \\
Actinomicetos & 2 & $3,33 \%$ \\
Acinetobacter sp & 1 & $3,33 \%$ \\
Moraxella spp & 1 & $3,33 \%$ \\
Pseudomonas pseudoalcaligenes & 1 & $3,33 \%$ \\
Pseudomonas putida & 1 & $3,33 \%$ \\
Staphylococcus capitis & 1 & $3,33 \%$ \\
Staphylococcus chromogenes & 1 & $3,33 \%$ \\
\hline Microrganismos fúngicos & 1 & $\mathbf{\%}$ \\
\hline Malassezia pachydermatis & 1 & $10 \%$ \\
Aspergillus sp & $\mathbf{n}^{\mathbf{0}}$ & $6,67 \%$ \\
Penicillium sp & 3 & $6,67 \%$ \\
Trichosporon sp & 2 & $3,33 \%$ \\
\hline
\end{tabular}

Tabela 2. Citologia das amostras de lavado broncoalveolar e correlação entre os parâmetros observados e as contagens bacterianas totais de cães hígidos.

Parâmetro

\section{Escores na citologia}

\begin{tabular}{|c|c|c|c|c|c|c|}
\hline & $\mathbf{0}$ & 1 & 2 & 3 & $\mathbf{r}$ & p-value \\
\hline Macrófagos alveolares & $\mathrm{n}=2(6,67 \%)$ & $\begin{array}{c}\mathrm{n}=13 \\
(43,33 \%)\end{array}$ & $\begin{array}{c}\mathrm{n}=10 \\
(33,33 \%)\end{array}$ & $\mathrm{n}=2(6,67 \%)$ & 0,4653 & $0,0096^{*}$ \\
\hline Células epiteliais & $\begin{array}{l}\mathrm{n}=27 \\
(90 \%)\end{array}$ & $\begin{array}{c}n=3 \\
(10 \%)\end{array}$ & $\begin{array}{c}\mathrm{n}=0 \\
(0 \%)\end{array}$ & $\begin{array}{l}\mathrm{n}=0 \\
(0 \%)\end{array}$ & 0,08361 & 0,6605 \\
\hline Hemácias integras & $\begin{array}{l}n=12 \\
(40 \%)\end{array}$ & $\begin{array}{c}n=7 \\
(23,33 \%)\end{array}$ & $\begin{array}{c}n=7 \\
(23,33 \%)\end{array}$ & $\begin{array}{c}n=4 \\
(13,33 \%)\end{array}$ & 0,06433 & 0,7356 \\
\hline $\begin{array}{l}\text { Macrófagos alveolares } \\
\text { espumosos }\end{array}$ & $\begin{array}{c}n=29 \\
(96,67 \%)\end{array}$ & $\begin{array}{l}\mathrm{n}=0 \\
(0 \%)\end{array}$ & $\mathrm{n}=1(3,33 \%)$ & $\begin{array}{c}n=0 \\
(0 \%)\end{array}$ & 0,1630 & 0,3894 \\
\hline $\begin{array}{l}\text { Células epiteliais } \\
\text { escamosas }\end{array}$ & $\begin{array}{l}n=24 \\
(80 \%)\end{array}$ & $\mathrm{n}=2(6,67 \%)$ & $n=2(6,67 \%)$ & $\mathrm{n}=2(6,67 \%)$ & 0,1490 & 0,4318 \\
\hline Bactérias & $\begin{array}{c}\mathrm{n}=29 \\
(96,67 \%)\end{array}$ & $\begin{array}{l}\mathrm{n}=0 \\
(0 \%)\end{array}$ & $\mathrm{n}=1(3,33 \%)$ & $\begin{array}{l}n=0 \\
(0 \%)\end{array}$ & $-0,1630$ & 0,3894 \\
\hline Eosinófilos & $\begin{array}{l}n=24 \\
(80 \%)\end{array}$ & $\begin{array}{c}n=6 \\
(20 \%)\end{array}$ & $\begin{array}{l}n=0 \\
(0 \%)\end{array}$ & $\begin{array}{l}n=0 \\
(0 \%)\end{array}$ & 0,1986 & 0,2929 \\
\hline Neutrófilos & $\begin{array}{c}\mathrm{n}=23 \\
(76,67 \%)\end{array}$ & $\begin{array}{c}n=6 \\
(20 \%)\end{array}$ & $\mathrm{n}=1(3,33 \%)$ & $\begin{array}{l}n=0 \\
(0 \%)\end{array}$ & 0,2098 & 0,2659 \\
\hline
\end{tabular}

correlação com contagens bacterianas totais

$\mathrm{r}=$ coeficiente de correlação de Spearman, * = significância estatística ao nível de 5\% 
Os isolamentos bacterianos positivos a partir de cães sadios, reforçam a idéia do uso concomitante da citologia do fluido recolhido durante o lavado para definir o diagnóstico em situações de dúvida (JOHNSON; FALES, 2001). A correlação positiva entre presença de macrófagos pulmonares e contagens bacterianas totais, observados no presente trabalho, pode indicar a existência de infecções pulmonares subclínicas nos animais pesquisados, apesar dos neutrófilos serem considerados como as principais células detectadas no lúmen traqueal de cães com pneumonia (DAMBRO et al., 1992). Uma vez que os macrófagos são especialmente importantes na defesa antibacteriana do trato respiratório, fatores que afetem sua capacidade fagocitária negativamente, como choque endotóxico podem predispor a infecções pulmonares nosocomais (JACOBS et al., 1986). Nos cães estudados, as outras populações celulares não foram correlacionadas às contagens bacterianas totais.

A presença de bactérias no lúmen traqueal, na ausência de células inflamatórias como neutrófilos, já foi descrita (JOHNSON; FALES, 2001). Considerando que os processos infecciosos pulmonares desencadeados por patógenos como Bordetella bronchiseptica nos cães evocam principalmente a presença de neutrófilos no lúmen traqueal (DAMBRO et al., 1992), recomenda-se que tanto a citologia como a cultura microbiológica sejam utilizadas simultaneamente para diagnóstico de pneumonias nos cães.

O isolamento de apenas uma espécie bacteriana por lavado broncoalveolar foi um evento raro no presente trabalho, o que não parece ocorrer nos casos de infecções pulmonares caninas, quando em quase metade das situações encontra-se somente uma única espécie (ANGUS; JANG; HIRSH, 1997).

Streptococcus não-hemolítico foi isolado em $13,3 \%$ dos animais pesquisados. O papel destas bactérias nas pneumonias caninas parece ser limitado, uma vez que muitos dos casos de pneumonia estreptocóccica canina relatados são desencadeados por espécies hemolíticas (GARNETT et al., 1982; ANGUS; JANG; HIRSH, 1997).

S. aureus já foi isolado de outros sítios anatômicos dos cães como o conduto auditivo externo e tegumento dos cães (KROGH; KRISTENSEN, 1981; YOSHIDA; NAITO; FUKATA, 2002), podendo ser considerado como parte da microbiota comensal dos cães, atuando como patógeno oportunista quando ocorrem fatores predisponentes. Deve-se considerar que, estando presente no trato respiratório dos cães, esta espécie pode ser capaz de provocar quadros pneumônicos quando fatores imunossupressivos como doenças intercorrentes e estresse manifestam-se nos cães, uma vez que as espécies coagulase-positivas são implicadas em casos de pneumonia canina (ANGUS; JANG; HIRSH, 1997). A colonização do trato respiratório dos cães por $S$. aureus pode ser especialmente importante quando esta bactéria expressa múltipla resistência a antimicrobianos (PAK; HAN; SHIMIZU, 1999). Seu isolamento a partir dos cães pesquisados é, portanto, significativo devido ao seu potencial patogênico.

Micrococcus varians e Micrococcus luteus foram isolados de quase um terço dos animais pesquisados. Estas espécies bacterianas podem ocorrer comumente no sistema tegumentar dos cães (KLOOS; ZIMMERMAN; SMITH, 1976; KROGH; KRISTENSEN, 1976) e seu encontro no trato respiratório dos animais pode ser reflexo da contaminação cruzada entre estes sítios anatômicos, devendo ser considerado como patógeno pulmonar, apenas em situações onde atue como oportunista (ADANG et al., 1992).

Dos bastonetes gram-negativos nãofermentadores da glicose isolados no presente trabalho, os gêneros Moraxella, Bordetella e Pseudomonas são importantes por que geralmente estão envolvidos em infecções oportunistas e primárias do trato respiratório. Conjuntamente com outras espécies de bastonetes desta categoria, podem ser isolados de até $10 \%$ das amostras clínicas oriundas de cães (MATHEWSON; SIMPSON, 1982) 
e são descritos como capazes de colonizar o lúmem traqueal canino (JOHNSON; FALES, 2001). A espécie Bordetella bronchiseptica é considerada uma das mais importantes na gênese das pneumonias caninas, sendo uma das causas do complexo tosse dos canis (MCCANDLISH et al., 1978). No presente trabalho, $10 \%$ dos animais estavam colonizados por esta espécie, indicando a possibilidade dos cães serem portadores inaparentes da mesma. Isto é considerado importante na manutenção da traqueobronquite infecciosa na população canina, pois a excreção da bactéria pós-infecção pode perdurar por 2 a três meses (BEMIS; CARMICHAEL; APPEL, 1977). É importante reconhecer também que mesmo cães portadores da $B$. bronchiseptica podem vir a desenvolver quadros pneumônicos, quando fatores imunossupressivos com a infecção pelo vírus da cinomose ocorrer nos animais (CORCORAN, 2004).

A utilização da técnica de lavado broncoalveolar para indentificação de pneumonias fúngicas em pequenos animais já foi utilizada, sendo recomendada para este diagnóstico (HAWKINS; DENICOLA, 1990). No presente trabalho, a ausência de microrganismos fúngicos na maioria das amostras sugere que estes são pouco representativos da microbiota traqueal canina, não sendo sua presença associada a de células inflamatórias.

Os gêneros fúngicos encontrados são considerados oportunistas, colonizando os pulmões quando processos imunossupressivos estão estabelecidos (WATT et al., 1995). As leveduras do gênero Malassezia, encontradas em 10\% dos animais pesquisados não foram relatadas como causadoras de penumonias em cães, sendo consideradas importantes nas otopatias caninas e raramente colonizam os sítios mucosos dos animais (BOND; SAIJONMAA-KOULUMIES; LLOYD, 1995; CRESPO; ABARCA; CABANES, 2002). Sua presença no lúmen traqueal é provavelmente decorrente da contaminação cruzada com outros sítios anatômicos.

\section{Conclusão}

A técnica transtraqueal para obtenção do lavado broncoalveolar não broncoscópico mostrou-se segura e a quantidade de material obtida foi suficiente para a avaliação citológica e microbiológica. Os macrófagos alveolares foram os tipos celulares predominantes na citologia. O contingente bacteriano que compõe a microflora existente no lúmen traqueal de cães hígidos varia em quantidade, sendo as espécies gram-positivas dominantes sobre as gramnegativas. Patógenos pulmonares como a Bordetella bronchiseptica e Staphylococcus aureus colonizam o lúmen traqueal de cães hígidos.

\section{Referências}

ADANG, R. P.; SCHOUTEN, H. C.; VAN TIEL, F. H.; BLIJHAM, G. H. Pneumonia due to Micrococcus spp. in a patient with acute myeloid leukaemia. Leukemia, Baltimore, v. 6, n. 3, p. 224-226, 1992.

ANGUS, J. C.; JANG, S. S.; HIRSH, D. C. Microbiological study of transtracheal aspirates from dogs with suspected lower respiratory tract disease: 264 cases (1989-1995). Journal of the American Veterinary Medical Association, Schaumburg, v. 210, n. 1, p. 55-58, 1997.

BEMIS, D. A.; CARMICHAEL, L. E.; APPEL, M. J. Naturally occurring respiratory disease in a kennel caused by Bordetella bronchiseptica. The Cornell Veterinarian, New York, v. 67, n. 2, p. 282-293, 1977.

BERKWITT, L.; PRUETER, J. Métodos diagnósticos para distúrbios respiratórios. In: BICHARD, S.J.; SHERDING, R. G. Manual Saunders: clínica de pequenos animais. São Paulo: Rocca, 1998. p. 592-597.

BOND, R.; SAIJONMAA-KOULUMIES, L.; LLOYD, D. H. Population sizes and frequency of Malassezia pachydermatis at skin and mucosal sites on healthy dogs. The Journal of Small Animal Practice, Oxford, v. 36, n. 4, p. 147-150, 1995.

COLLEGE OF VETERINARY MEDICINE - CVM. Tracheal wash. Disponível em: <http://www.cvm.missouri.edu/cvm/ rmr/traqueal\%20wash.html>. Acesso em: 14 jul. 2004.

CORCORAN, B. Avaliação clínica do paciente com doença respiratória. In: . Tratado de Medicina Interna Veterinária. Philadelphia: Manole, 2004. v. 3, p. 1090-1096. 
CRESPO, M. J.; ABARCA, M. L.; CABANES, F. J. Occurrence of Malassezia spp. in the external ear canals of dogs and cats with and without otitis externa. Medical Mycology, Oxford, v. 40, n. 2, p. 115-121, 2002.

CURI, P. R. Metodologia e análise da pesquisa em ciências biológicas. Botucatu: Timpomic, 1997.

DAMBRO, N. N.; GRAD, R.; WITTEN, M. L.; QUAN, S. F.; SOBONYA, R. E.; RAY, C. G.; LEMEN, R. J. Bronchoalveolar lavage fluid citology reflects airway inflamation in beagle puppies with acute bronchiolitis. Pediatric Pulmonology, Phyladelphia, v. 12, n. 4, p. 213220, 1992.

GARNETT, N. L.; EYDELLOTH; R. S.; SWINDLE, M. M.; VONDERFECHT, S. L.; STRANDBERG, J. D.; LUZARRAGA, M. B. Hemorrhagic streptococcal pneumonia in newly procured research dogs. Journal of the American Veterinary Medical Association, Schaumburg, v. 181, n. 11, p. 1371-1374, 1982.

HAWKINS, E. C. Cytological analysis of bronchoalveolar lavage fuid in the diagnosis of spontaneous respiratory tract disease in dogs: a retrospective study. Journal of Veterinary Internal Medicine, Philadelphia, v. 9, n. 6, p. 386-392, 1995.

Distúrbios do sistema respiratório. In:

Medicina interna de pequenos animais. 3. ed. Rio de Janeiro: Mosby, 2006. p.247-27.

HAWKINS, E. C.; DENICOLA, D. B. Cytologic analysis of tracheal wash specimens and bronchoalveolar lavage fluid in the diagnosis of mycotic infections in dogs. Journal of the American Veterinary Medical Association, Schaumburg, v. 197, n. 1, p. 79-83, 1990.

JACOBS, R. F.; DORSEY, D. R.; TRYKA, A. F.; TABOR, D. R. Pulmonary macrophage antimicrobial activity in canine endotoxin shock and lung injury. Experimental Lung Research, New York, v. 14, n. 3, p. 359-374, 1986.

JOHNSON, L. R.; FALES, W. H. Clinical and microbiologic findings in dogs with bronchoscopically diagnosed tracheal collapse: 37 cases (1990-1995). Journal of the American Veterinary Medical Association, Schaumburg, v. 219, n. 9, p. 1247-1250, 2001.

KLOOS, W. E.; ZIMMERMAN, R. J.; SMITH, R. F. Preliminary studies on the characterization and distribution of Staphylococcus and Micrococcus species on animal skin. Applied and Environmental Microbiology, Washington, v. 31, n. 1, p. 53-59, 1976.
KROGH, H. V.; KRISTENSEN, S. A study of skin diseases in dogs and cats. II. Microflora of the normal skin of dogs and cats. Nordisk Veterinaermedicin, Copenhagen, v. 28, n. 9, p. 459-463, 1976.

A study of skin diseases in dogs and cats. VI. Microflora of the major canine pyodermas. Nordisk Veterinaermedicin, Copenhagen, v. 33, n. 1, p. 17-22, 1981.

LACAZ, C. S.; PORTO, E.; HEINS-VACCARI, E. M.; MELO, N. T. Guia para indentificação de fungos, actinomicetos e algas de interesse médico. São Paulo: Sarvier, 1998.

MATHEWSON, J. J.; SIMPSON, R. B. Glucosenonfermenting Gram-negative bacilli associated with clinical veterinary specimens. Journal of Clinical Microbiology, Washington, v. 15, n. 6, p. 1016-1018, 1982.

MCCANDLISH, I. A.; THOMPSON, H.; CORNWELL, H. J.; WRIGHT, N. G. A study of dogs with kennel cough. The Veterinary Record, London, v. 102, p. 293-301, 1978.

McCUllough, S.; BRINSON, J. Collection and interpretation of respiratory cytology. Clinical Techniques in Small Animal Practice, Philadelphia, v.14, n.4, p. 220226, 1999.

PADRID, P. A. Pulmonary diagnostics. Veterinary Clinics of North America: Small Animal Practice, Philadelphia, v. 30, n. 6, p. 1187-1206, 2000.

PAK, S. I.; HAN, H. R.; SHIMIZU, A. Characterization of methicillin-resistant Staphylococcus aureus isolated from dogs in Korea. The Journal of Veterinary Medical Science, Tokyo, v. 61, n. 9, p. 1013-1018, 1999.

QUINN, P. J.; CARTER, M. E.; MARKEY, B.; CARTER, G. R. Clinical Veterinary Microbiology. London: Wolfe, 1994.

TYLER, R. D.; COWELL, R. L.; MEINKOTH, J. H.; DeNICOLA, D. B. Introduction. In:___ Diagnostic citology and hematology of the dog and cat. London: Mosby, 1999. p. 1-19.

WATT, P. R.; ROBINS, G. M.; GALLOWAY, A. M., O'BOYLE, D. A. Disseminated opportunistic fungal disease in dogs: 10 cases (1982-1990). Journal of the American Veterinary Medical Association, Schaumburg, v. 207 , n. 1, p. $67-70,1995$.

YOSHIDA, N.; NAITO, F.; FUKATA, T. Studies of certain factors affecting the microenvironment and microflora of the external ear of the dog in health and disease. Journal of Veterinary Medical Science, Tókio, v. 64, n. 12, p. 1145 1147, 2002. 